\title{
Integrity and Corruption in the Health Sector in Jordan: The Perceptions of Leaders of Non-government Health Organizations (NGHOs)
}

\author{
Musa T. Ajlouni ${ }^{1}$ \\ ${ }^{1}$ Faculty of Administrative and Financial Sciences, Philadelphia University, Amman, Jordan \\ Correspondence: Musa T. Ajlouni, Faculty of Administrative and Financial Sciences, Philadelphia University, \\ Amman, Jordan. E-mail: ajluni1@gmail.com
}

Received: December 12, 2016

Accepted: January 4, 2017

Online Published: January 6, 2017

doi:10.5539/ibr.v10n2p95

URL: http://dx.doi.org/10.5539/ibr.v10n2p95

\begin{abstract}
Corruption is a complex social and economic phenomenon which does not only threaten equity, but also health outcomes. This study aims at identifying corruption practices in the health sector in Jordan, factors that promote these practices and policy directions to control them as perceived by leaders of non-government health care organizations (NGHOs). The study adopted both qualitative and quantitative approaches. 24 NGHOs leaders participated in a one -day workshop and were divided into three sub-groups to address areas of corruption in the health sector in Jordan based on a conceptual model which addresses corruption according to the main actors, namely: regulators, providers, payers, patients and suppliers. The findings of the three sub-groups were put together by the researcher and were sent to the participants by email for validation and ranking.

The results showed that organizers' corruption was mainly manifested in favoritism, seeking personal interest, failure to base decisions on evidence and accepting bribes from suppliers. Corruption among providers was perceived mainly in nepotism and favoritism among doctors, especially in malpractice cases, evasion of taxes and fees and overcharging patients. Corruption caused by suppliers was manifested in tax evasion, bribing and fraud. Corruption caused by patients was perceived in trying to get free care by under reporting their income, deceiving insurers to obtain benefits and stealing and vandalism. Corruption related to health insurers was manifested in tax evasion, incapacitating patients and delaying approvals of claims and unjustified deductions on patients' bills. Causes of corruption and interventions to improve integrity in the health sector were also addressed by the participants.
\end{abstract}

Keywords: corruption, health sector, integrity, non-government health care organizations

\section{Introduction}

Jordan has one of the most modern health care infrastructures in the Middle East. The country's health system consists of two major sectors: public and private. The public sector has two sub-sectors that finance as well as deliver care: the Ministry of Health (MOH) and the Royal Medical Services. Other smaller semi-public providers include two university hospitals: the Jordan University Hospital in Amman and the King Abdullah Hospital in Irbid. The private sector includes 61 hospitals and many private clinics. Over 1.6 million Palestinian refugees in Jordan get access to primary care through the United Nations Relief Works Agency (Ajlouni, 2010). Problems related to equity, duplication of services, poor coordination among major providers, unregulated private sector, inefficient use of available resources, poor management, the influx of Syrian refugees, and inappropriate health information systems are the main challenges facing all providers of health care in Jordan (Ajlouni, 2010)

Integrity as defined by the Oxford dictionary means: "the quality of being honest and having strong moral principles". Transparency International defines corruption as "the abuse of entrusted power for private gain". Corruption is a multifaceted social, political, ethical, and economic episode that affects all countries. Corruption affects negatively democratic institutions, slows economic development indicators creates unstable political systems (Transparency International, 2006).

In the health sector, corruption is defined by Nishtar (2007) as "actions of stakeholders within the health system mandated with governance and regulatory roles, or those that have a role in the delivery of services and/or providing input to the system, which are not legally provided for and which do or have the potential to do 
damage to the public or its interests". Examples of corruption may include paying-off regulators and medical professionals, exploitation of information on drug trials, the distraction of medicines and supplies and corruption in procurement and the overbilling of insurance companies (Savedoff and Hussmann, 2006; Vian, 2007). An average of 5.59 percent of annual global health spending (about US\$ 4.7 trillion) is lost due to fraud (United Nations Development Program/UNDP, 2011).

Only a few studies about integrity and corruption in the health sector in Jordan exist, all of these studies were related to pharmaceutical services. These studies revealed that the areas of medicine distribution and procurement are minimally vulnerable to corruption; medicines registration and selection are marginally vulnerable to corruption; medicine inspection is moderately vulnerable to corruption; while medicine promotion is extremely vulnerable to corruption (World Health Organization/WHO, 2007; Hamra et al., 2007).

This study is designed to achieve the following objectives:

(1) Identifying corruption practices and factors or circumstances that promote these practices in the health sector in Jordan as perceived by the leaders of non-government health organizations (NGHOs).

(2) Suggesting policy directions and interventions to promote integrity and prevent corruption in the health sector in Jordan.

\section{Methodology and Tools}

This study adopted the conceptual model for corruption in the health sector (Figure 1) which was developed by Savedoff and Hussmann (2006) and has been used in most recent studies about corruption in the health sector. The model identifies major actors of the health sector who could be involved in corruption practices: government regulators (health ministries, parliaments, specialized commissions); payers (social security institutions, government office, private insurers); providers (hospitals, doctors, pharmacists); consumers (patients); and suppliers (medical equipment and pharmaceutical companies). It also indicates the most common corruption practices for each sector as revealed from reported research.

The study utilized both qualitative and quantitative approaches. The following methods were used to collect data and achieve the objectives of the study:

(1) Related studies and reports about integrity and corruption practices in the health sector were reviewed and the main areas of corruption for each health actor were listed (Annex 1) according to the study conceptual model.

(2) 40 leaders of non - government healthcare organizations (NGHOs) listed on the web site of the "Guide to Civil Society Organizations in Jordan" were invited by email and telephone calls to attend a one- day workshop to: identify areas of corruption in the health sector, suggest causes of corruption and propose policy directions to reduce corruption. Also, representatives from medical and nursing associations, media and former ministers of health were invited to attend this workshop. Only 24 leaders were willing to participate (18 from NGHOs, two journalists, two former ministers of health and two representatives from Jordan health associations. Representatives from Jordanian Anti-Corruption Commission, Jordan High Health Council and United Nation Development Program (UNDP) attended the workshop as observers.

(3) In the first session of the workshop, the researcher gave a presentation about: study objectives, integrity definition, corruption in the health sector, the reasons behind corruption in the health sector, global situation of integrity in the health sector as reported in literature.

(4) In the second session, the participants were divided into three working groups to discuss integrity and corruption in the health sector in Jordan. The participants were provided by a discussion guide comprising corruption areas based on the study conceptual model to facilitate the discussion towards achieving the study objectives (Annex 1). The members in each working group were encouraged to add, delete or amend on the contents of the guide or even ignore them and propose their own input. The participants were asked to discuss the following themes: areas of lack of integrity for each actor in the health sector in Jordan from the participants' perspectives; the reasons behind the presence of corruption in the health sector in Jordan; and solutions including health policies which may help in reducing corruption in the health sector in Jordan. 


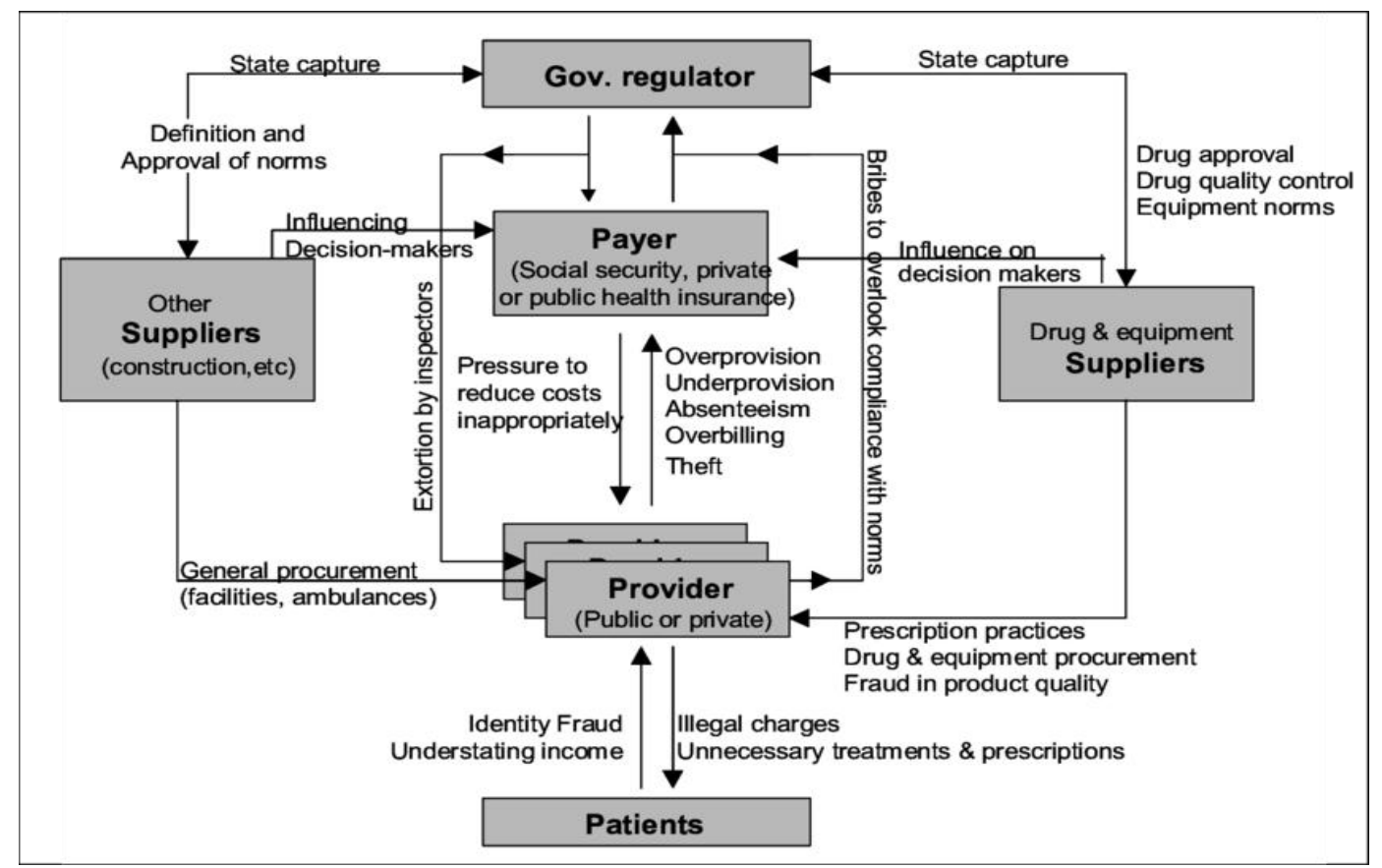

Figure 1. Conceptual Model for Corruption in the Health Sector

Source: Savedoff and Hussmann, Five Key Actors in the Health System, source: Chapter 1, the causes of corruption in the health sector, in Transparency International (Ed.), Global Corruption Report 2006.

Each working group was asked to report back to the whole group the perceptions of its members about each of the discussion themes. The researcher put together the reports of the three working groups in one table arranged according to areas of corruption in the health sector in Jordan for each actor (government regulators, providers, patients, suppliers, and health insurers). The table then was sent to the participants by email to validate and rank the identified areas of corruption according to the degree of prevalence by using Likert five point scale (1 very low, 2 low, 3 medium, 4 high, 5 very high). 20 out of 24 members (83\%) responded and sent validation and ranking back to the investigator. The arithmetic mean (average score) and standard deviation were calculated for each area of corruption and the results were presented in tables according to each actor in the health sector.

\section{Study Limitations}

Due to time and budget constraints, this study was confined to community based health organizations and the participants were not randomly selected. Thus, the findings do not necessarily reflect the perceptions of other stakeholders (i.e. organizers, providers, patients, suppliers, payers). Since this is the first study about corruption in the health sector in Jordan, it serves mainly as a tool for "break the ice" in this area. More comprehensive studies that include all stakeholders are urgently needed.

\section{Findings}

\subsection{Areas of Corruption in the Health Sector as Perceived by Leaders of None Government Health Organizations}

The participants identified many different corruption areas in the health sector in Jordan related to the organizers, providers, suppliers, patients and health care insurers.

\subsubsection{Areas of Corruption Caused by Healthcare Organizers}

Table 1 below shows the areas of corruption caused by healthcare organizers as perceived by the participants. "Favoritism in recruitment, hiring, transfer and promotion and training opportunities and the absence of justice and transparency" was perceived as the most prevalent area of corruption practiced by healthcare organizers and got the highest score ( 4.4 scores), followed in descended order by "make administrative decisions or use of formal position to achieve personal interest"( 4.2 scores), "favoritism and nepotism exempting certain parties from fees or taxes or reducing them without legal justification" (3.0 scores), "accept bribes from suppliers or other stakeholders" (2.6 scores), "buy materials or equipment or build and rent health facilities without a real need for their own interests ( 2.1 scores), and manipulate official documents (2.0 scores). 
Table 1. Areas of Corruption Caused by Healthcare Organizers as Perceived by NGHOs Leaders Presented According to Rank Order and Average Score

\begin{tabular}{clcc}
\hline $\begin{array}{c}\text { Rank } \\
\text { Order }\end{array}$ & \multicolumn{1}{c}{ Areas of Corruption } & $\begin{array}{c}\text { Average } \\
\text { Score }\end{array}$ & SD \\
\hline $\mathbf{1}$ & $\begin{array}{l}\text { Favoritism in recruitment, hiring, transfer and promotion and training } \\
\text { opportunities and the absence of justice and transparency. }\end{array}$ & 4.4 & 0.65 \\
$\mathbf{2}$ & $\begin{array}{l}\text { Make administrative decisions or use of formal position to achieve personal } \\
\text { interest or the interests of the parties close to the decision-maker. }\end{array}$ & 4.2 & 0.53 \\
$\mathbf{3}$ & $\begin{array}{l}\text { Favoritism and nepotism (exempting certain parties from fees or taxes or } \\
\text { reducing them without legal justification). }\end{array}$ & 3.0 & 0.34 \\
$\mathbf{4}$ & $\begin{array}{l}\text { May accept bribes from suppliers or other stakeholders to accept material or } \\
\text { contract breach or overlook lapses in licensing requirements. }\end{array}$ & 2.6 & 0.41 \\
$\mathbf{5}$ & $\begin{array}{l}\text { Buy materials or equipment or build and rent health facilities without a real } \\
\text { need for their own interests. }\end{array}$ & 2.1 & 0.39 \\
$\mathbf{6}$ & Manipulate official documents. & 2.0 & 0.54 \\
\hline
\end{tabular}

4.1.2 Areas of Corruption Caused by the Health Care Providers

Table 2 below shows the areas of corruption caused by health care providers as perceived by the participants. The most prevalent areas of corruption practiced by the health care providers in Jordan with an average score of $>$ 4 are: "Nepotism and favoritism among doctors, especially in malpractice cases" (4.2 scores), "evasion of taxes and fees" ( 4.1 scores), "overcharging patients" ( 4.1 scores), and "high pre-admission deposit required by private hospitals and delay of patient care especially for emergency and accident cases ( 4.0 scores)". Areas of corruption as: wasting resources in the public health sector, the high price of medicine, violation of patients' rights, leniency in the application of patient safety procedures, taking bribes from suppliers, abusing job and absenting from public jobs were perceived as less frequent than the above practices with an average score ranging from 3.9 to 3.0.

Other areas of corruption as requesting many unneeded procedures, prescribing expensive drugs in exchange for kickbacks, thefts, referring patients to other providers for financial gains, paying commission for mediators, performing medical procedures without authorization, and informal payments were perceived by the participants as not happening frequently (low prevalence) with an average score ranging from 2.5 to 1.7.

Table 2. Areas of Corruption Caused by Health Care Providers as Perceived by NGHOs Leaders Presented According to Rank Order and Average Score

\begin{tabular}{|c|c|c|c|}
\hline $\begin{array}{l}\text { Rank } \\
\text { Order }\end{array}$ & Areas of Corruption & $\begin{array}{l}\text { Average } \\
\text { Score }\end{array}$ & SD \\
\hline 1 & Nepotism and favoritism among doctors, especially in malpractice cases & 4.2 & 0.36 \\
\hline 2 & Evasion of taxes and fees & 4.1 & 0.35 \\
\hline 3 & Overcharging patients especially from other Arab countries & 4.1 & 0.67 \\
\hline 4 & $\begin{array}{l}\text { High pre-admission deposit required by private hospitals and delay of patient } \\
\text { care, especially for emergency and accident cases }\end{array}$ & 4.0 & 0.36 \\
\hline 5 & $\begin{array}{l}\text { Wasting resources in the public health sector and the low percentage of } \\
\text { utilization in some health centers }\end{array}$ & 3.9 & 0.35 \\
\hline 6 & $\begin{array}{l}\text { The high price of medicine in Jordan (the existing medicine pricing system } \\
\text { followed by Food and Drug Administration is not fair) }\end{array}$ & 3.8 & 0.67 \\
\hline 7 & $\begin{array}{l}\text { Violation of patients' rights (not providing privacy during diagnosis, lack of } \\
\text { good communication, lack of clinical examination) }\end{array}$ & 3.8 & 0.41 \\
\hline 8 & $\begin{array}{l}\text { Leniency in the application of some of the necessary safety procedures and } \\
\text { sterilization in healthcare facilities }\end{array}$ & 3.7 & 0.33 \\
\hline 9 & $\begin{array}{l}\text { Taking bribes from suppliers in order to accept materials or services not in } \\
\text { conformity with the specifications }\end{array}$ & 3.5 & 0.73 \\
\hline 10 & Abusing job by coming late, leaving early or absenteeism & 3.4 & 0.46 \\
\hline 11 & $\begin{array}{l}\text { Absenting themselves from public jobs to provide private consultations } \\
\text { elsewhere }\end{array}$ & 3.0 & 0.34 \\
\hline 12 & Requesting many unneeded procedures and tests for patients for financial gains & 2.5 & 0.36 \\
\hline 13 & $\begin{array}{l}\text { Prescribing expensive drugs in exchange for kickbacks or bribes from } \\
\text { pharmaceutical companies }\end{array}$ & 2.5 & 0.67 \\
\hline 14 & Thefts of drugs and medical supply & 2.4 & 0.81 \\
\hline 15 & $\begin{array}{l}\text { Referring patients to a certain pharmacy, laboratory, doctor, X-ray center for } \\
\text { financial gains }\end{array}$ & 2.4 & 0.45 \\
\hline 16 & $\begin{array}{l}\text { Paying commission for mediators to bring patients to specific provider or } \\
\text { hospital }\end{array}$ & 2.1 & 0.36 \\
\hline 17 & Performing medical procedures without authorization from official bodies & 2.1 & 0.35 \\
\hline 18 & $\begin{array}{l}\text { Taking bribes from patients for services that are supposed to be free (Informal } \\
\text { payments) }\end{array}$ & 1.7 & 0.67 \\
\hline
\end{tabular}




\subsubsection{Areas of Corruption Caused by Suppliers}

Table 3 below shows the areas of corruption caused by healthcare suppliers as perceived by the participants. The most prevalent areas of corruption practiced by suppliers with an average score $>4$ as perceived by the participants are: "Tax evasion" ( 4.3 score) and bribing physicians to encourage them to prescribe their products" (4.1 score). Other areas of corruption as: bribing purchasing officers to approve their offers or goods, fraud or deception in order to sell materials which are below standards, and bids corruption have been perceived as being less prevalent with average scores of (3.9),(3.8) and (3.3) respectively.

Table 3. Areas of Corruption Caused by Suppliers as Perceived by NGHOs Leaders Presented According to Rank Order and Average Score

\begin{tabular}{clcc}
\hline $\begin{array}{l}\text { Rank } \\
\text { Order }\end{array}$ & \multicolumn{1}{c}{ Areas of Corruption } & $\begin{array}{c}\text { Average } \\
\text { Score }\end{array}$ & SD \\
\hline $\mathbf{1}$ & Tax evasion & 4.3 & 0.26 \\
$\mathbf{2}$ & $\begin{array}{l}\text { Pharmaceutical companies may bribe physicians to encourage them to prescribe } \\
\text { their products (provide financial support for their trips, provide gifts, sponsor }\end{array}$ & 4.1 & 0.35 \\
$\mathbf{3}$ & $\begin{array}{l}\text { abroad conferences or support their clinics with equipment) } \\
\text { Bribe purchasing officers or decision makers to approve their offers or goods }\end{array}$ & 3.9 & 0.67 \\
$\mathbf{4}$ & $\begin{array}{l}\text { Fraud and deception in order to sell materials which are below standards and } \\
\mathbf{5}\end{array}$ & 3.8 & 0.44 \\
\hline required specifications & 3.3 & 0.40 \\
\hline
\end{tabular}

Five areas of corruption caused by patients were perceived by the participants with average score ranging from (3.6) to (2.4) as shown in table 4 below. Under reporting income to get free or subsidized care was seen as the most frequent area of corruption among patients (3.6 score), followed with bribing or deceiving a doctor to obtain benefits for non-health issues ( 3.5 score), using the insurance cards of friends or family members (2.6 score), stealing materials from health facilities ( 2.5 score), and vandalism to health facilities ( 2.4 score).

Table 4. Areas of Corruption Caused by Patients as Perceived by NGHOs Leaders Presented According to Rank Order and Average Score

\begin{tabular}{clcc}
\hline $\begin{array}{l}\text { Rank } \\
\text { Order }\end{array}$ & \multicolumn{1}{c}{ Areas of Corruption } & $\begin{array}{c}\text { Average } \\
\text { Score }\end{array}$ & SD \\
\hline $\mathbf{1}$ & Try to get free or subsidized care by under reporting their income & 3.6 & 0.28 \\
$\mathbf{2}$ & Bribe or deceive a doctor to obtain benefits for non-health issues & 3.5 & 0.35 \\
$\mathbf{3}$ & Misrepresent their enrollment in an insurance plan by using the insurance cards of & 2.6 & 0.53 \\
$\mathbf{4}$ & friends or family members & 2.5 & 0.78 \\
$\mathbf{5}$ & Stealing materials from health facilities and hospitals & 2.4 & 0.36 \\
\hline
\end{tabular}

4.1.5 Areas of Corruption Caused by Health Insurers or Payers

Table 5 below shows the areas of corruption caused by health insurers or payers. The most prevalent areas of corruption practiced by health insurers as perceived by the participants is: "Tax evasion" ( 4.0 score) followed by incapacitate patients and delay approvals (3.5 score), unjustified deductions for patients' bills (3.4 score), inclusion of some patients to insurance plans retroactively ( 2.6 score), and bribe decision makers to approve their offers ( 2.3 score) .

Table 5. Areas of Corruption Caused by Health insurers or payers as Perceived by NGHOs Leaders Presented According to Rank Order and Average Score

\begin{tabular}{clcc}
\hline $\begin{array}{c}\text { Rank } \\
\text { Order }\end{array}$ & \multicolumn{1}{c}{ Areas of Corruption } & $\begin{array}{c}\text { Average } \\
\text { Score }\end{array}$ & SD \\
\hline $\mathbf{1}$ & Tax evasion. & 4.0 & 0.12 \\
$\mathbf{2}$ & $\begin{array}{l}\text { Incapacitate patients and delay approvals to urge them to do tests or procedures } \\
\text { at their own expense. }\end{array}$ & 3.5 & 0.44 \\
$\mathbf{3}$ & Unjustified deductions for patients' bills received from health care providers. & 3.4 & 0.67 \\
$\mathbf{4}$ & Inclusion of some patients with insurance plans retroactively to benefit from & 2.6 & 0.53 \\
$\mathbf{5}$ & allowances granted by providers. & 2.3 & 0.75 \\
\hline
\end{tabular}

4.2 Causes of Corruption in the Health Sector as Perceived by the Leaders of None-Government Health Organizations

The participants pointed out during the workshop discussions that corruption in the healthcare sector in Jordan is mainly attributed to:

- The absence or lack of clear performance standards. 
- Limitations of laws applications (the absence of sanctions and the lack of incentives).

- Community culture (presence of favoritism and nepotism).

- Weak accountability.

- The absence of monitoring and evaluation.

- The absence of justice and transparency.

- Low salaries and insufficient incentives to meet the requirements of living, particularly in the public sector.

- Low awareness of community responsibility.

- Lack of experience and technical capabilities of the administrative staff responsible for auditing, monitoring and follow-up.

- Weakness in some legislations and laws.

- Lack of clear policies and regulations.

- Lack of quality assurance mechanisms.

4.3 Interventions to Control Corruption in the Health Sector as Suggested by Leaders of None Government Health Organizations

The participants suggested the following interventions and policy directions to be followed by the health policy makers to fight and control corruption in the healthcare sector in Jordan:

- Approve and practice medical accountability law.

- Reconsidering health insurance system, mechanisms, coverage and procedures.

- Develop clear therapeutic polices and medical protocols which can be accessible to all.

- Decrease medication use and control medicine prescriptions exchange.

- Reconsidering health legislations and improve it according to international standards.

- Improve working environment and wages specially for public sector employees

- Promote a culture of integrity.

- Punish corrupts.

- Enhance Jordanian Anti- corruption Commission capacity.

- Provide training courses and scientific conferences to health care providers on regular and continuous basis to enhance their capacities and efficiency to provide effective services for patients.

- Raising awareness of patients and physicians regarding their rights and responsibilities.

- Activating monitoring system on the health sector.

\section{Discussion}

As reported by the Business Anti-Corruption Portal: Jordan Country Profile (2015), corruption in Jordan is manifested mainly in favoritism, nepotism or paying off (bribing). Favoritism and nepotism, as in the use of influence or personal and business relations to get favors such as jobs or access to goods and services, are covered by a particular concept known in Jordan as Wasta ('mediation').

Savedoff (2007) and Savedoff and Hussmann (2006) indicated that the existence of regulators opens avenues for corrupt activities. Pharmaceutical companies can distort research studies, influence review boards or bribe regulators to approve or speed up the processing of their applications. As in any sector, government inspectors can be tempted to abuse their position to get bribes even when providers are in conformity.

Savedoff and Hussmann (2006), UNDP (2011), Vian and Nordberg (2008), and Graber et al. (2005) reported that health care providers may practice corruption because they take important medical decisions as prescribing medications, determining admission and the length of a hospital stay, ordering tests and referring patients for additional consultations, services, procedures or investigations.

Contrary to the findings of this study, little evidence in literature was found that support pro-physician bias or favoritism among doctors in malpractice cases. Graber et al (2005) found that surveys of randomly selected physicians are feasible to perform for medical malpractice cases. A pro-physician bias has little if any influence on the results.

Tax evasion by health professionals, as revealed by this study, is a common problem in most countries, particularly in developing countries where the information and monitoring systems are weak (Mbilinyi, 2013). Over billing by doctors and hospitals is common practice in most countries. In the USA for example, it was 
reported that over billing costs Medicare a billion dollars a year (The Centre for Public Integrity, 2014). It is recommended that government authorities in Jordan should address seriously evasion of taxes and fees by health care providers and suppliers.

A technical paper on Albania health system financing and corruption prepared by the Council of Europe (2010) reported that it is a frequent practice for doctors to intentionally avoid using facilities and equipment available within the public hospitals for patient examinations, instead referring patients to private providers of the same services, with which the doctor has links. In addition, doctors over prescribe and suggest to patients the pharmacy where they can buy the prescribed medicines, in return receiving payments from the pharmacy.

It is widely reported that absenteeism in the health sector, as in other public sectors, is a common practice in developing countries. In Argentina it was found that absenteeism was the most common form of corruption among doctors and nurses in public hospitals. A survey in Costa Rica found that more than two-thirds of doctors and nurses indicated high levels of absenteeism in their hospitals (UNDP, 2011).

Though it was not a common practice as reported by the participants in this study, theft of drugs and medical supplies by health care professionals is common globally. In Venezuela, approximately two-thirds of hospital personnel surveyed were aware of theft of medical supplies and medications. Similarly, in Costa Rica, 71 percent of doctors and 83 percent of nurses reported that equipment or materials had been stolen in their hospital. One study in Uganda found that the resale of drugs represented the greatest single source of income for health care personnel (UNDP, 2011).

Bribing physicians by pharmaceutical companies to encourage them to prescribe their products as reported by the participants is a common practice also in many countries. It was reported by the Guardian newspaper on 3 July 2012 that pharmaceutical group GlaxoSmithKline has been fined \$3bn after admitting bribing doctors and encouraging the prescription of unsuitable antidepressants to children (Guardian newspaper, 2012).

The corruption practiced by patients was seen by the participants as less frequent than corruption practiced by healthcare organizers, providers and suppliers and was rated as moderate or less. This may be attributed to the fact that patients are fragile, weak and powerless compared to other stakeholders.

It is reported that in many health systems, patients try to get free or subsidized care by under reporting their personal or family income. In other systems, patients misrepresent their enrollment in an insurance plan by using the insurance cards of family members or friends. This has been documented in Canada, where the province of Ontario detected numerous people using counterfeit insurance cards to gain access to free public care. A patient may bribe a doctor to obtain benefits for non-health issues, such as a health certificate to obtain a driver's license, to avoid military service or to obtain disability payments (UNDP, 2011).

Private insurers may defraud public sector programs that subsidize health care through fraudulent billing. They may reject insurance claims that they are committed to reimburse. And they may bribe insurance regulators to ignore illegal practices (UNDP, 2011).

To conclude, corruption is a public health issue that will not disappear by itself, nor can it be ignored. Health policy makers in Jordan should admit that the health care system in Jordan, as the case in other countries, has many aspects of corruption that may vary in volume, prevalence rates, and impact. They should also recognize that it is possible to confront corruption by changing the conditions that allow it to happen and support it. Tackling corruption in the health sector is essential for achieving better health outcomes. The proposed interventions, as suggested by the participants, are highly recommended to tackle and control corruption in the health sector in Jordan.

\section{References}

Ajlouni, M. (2011). Jordan Health System Profile for 2010.A country report submitted to WHO EMRO).

Business Anti-Corruption Portal: Jordan Country Profile. (2015). http://www.business-anti-corruption.com/country-profiles/jordan

Council of Europe. (2010). A technical paper: Preliminary Analysis of Albania Health System Financing and Corruption.

http://www.coe.int/t/dghl/cooperation/economiccrime/corruption/projects/Albania/Technical\%20Papers/191 7-PACA\%20-TP-Jazaj-july10.pdf

Graber, M., Hartz, A., James, P., Nugen, A., \& Green, M. (2005). An Alternative Method of Determining Standard of Care in Alleged Cases of Malpractice. J Am Board Fam Med., 18(6), 453-458. https://doi.org/10.3122/jabfm.18.6.453 
Guardian newspaper. (2012). http://www.guardian.co.uk/business/2012/jul/03/glaxosmithkline-fined-bribing-doctors-pharmaceuticals

Guide to Civil Society Organizations in Jordan: http://www.civilsociety-jo.net/en/organizations/8/health-care-organizations?page=2

Hamra, R., Ferrario, A., Bigdeli, M., \& Baghdadi, G. (2007). Transparency Monitoring Study: A Rapid Assessment of Transparency in Key Functions of Pharmaceutical Services in 15 countries. WHO, Alliance for Health Policy and System Research, Nov. 2011.

Mbilinyi, A. (2013). Curbing Tax Evasion By Professional Service Providers In Tanzania. Tanzania Country Level Knowledge Network,Policy Brief No.5. http://clknet.or.tz/wp-content/uploads/2013/03/CURBING-TAX-EVASION_FV.pdf

Nishtar, S. (2007). Corruption in the health sector in Pakistan. Heartfile and Transparency International; 2007. http://www.heartfile.org/pdf/health-sector-corruption-pakistan.pdf

Oxford Dictionary. https://en.oxforddictionaries.com/explore/how-many-words-are-there-in-the-english-language

Savedoff, W. (2007). Transparency and Corruption in the Health Sector: A Conceptual Framework and Ideas for Action in Latin American and the Caribbean. Health Technical Note 03/2007,May 2007,Sustainable Development Department Social Programs Division Inter-American Development Bank Washington, D.C. http://idbdocs.iadb.org/wsdocs/getdocument.aspx?docnum=1481625

Savedoff, W., \& Hussmann, K. (2006). The causes of Corruption in the Health Sector. Global Corruption Report 2006, Transparency International, First published 2006 by Pluto Press.

The Centre for Public Integrity. (2014). Cracking the Codes: How doctors and hospitals have collected billions in questionable Medicare fees.

https://www.publicintegrity.org/2012/09/15/10810/how-doctors-and-hospitals-have-collected-billions-questi onable-medicare-fees

Transparency International's Global Corruption Report. (2006). Corruption and paying for health care 2006. https://issuu.com/transparencyinternational/docs/2006_gcr_healthsector_en?mode=window\&backgroundCo lor $=\% 23222222$

UNDP. (2011). Fighting Corruption in the Health Sector Methods, Tools and Good Practices. http://www.undp.org/content/undp/en/home/librarypage/democratic-governance/anti-corruption/fighting_co rruptioninthehealthsector/

Vian, T. (2007). Review of corruption in the health sector: theory, methods and interventions. Health Policy Plan, 23(2), 83-94.

Vian, T., \& Nordberg, C. (2008). Corruption in the Health Sector. Chr.Michelsen Institute. U4 ISSUE. http://www.u4.no/publications/corruption-in-the-health-sector-2/

WHO. (2007). Measuring transparency to improve good governance in the public pharmaceutical sector - Jordan, WHO/EMRO, 2009. http://applications.emro.who.int/dsaf/dsa968.pdf 


\section{Annex 1: Integrity in the Health Sector in Jordan: the Perception of Leaders of Non-Government Healthcare Organizations (NGHCOs)}

\section{Discussion Guide}

Three discussion groups will be formed to identify areas of corruption in the health sector in Jordan; identify causes of corruption; and suggest policy directions to combat corruption.

The following guide is presented to help the group in their discussions .The group is encouraged to add, delete or amend on the contents of the guide or even ignore them and propose their own input.

The Main actors in the health sector and example areas of corruptions as reported in literature

Regulators (ministries of health, parliaments, supervisory commissions)

- Pharmaceutical companies may bribe regulators to approve or speed up the processing of their applications.

- $\quad$ Private health care providers and facilities may pay a regulator to overlook lapses in licensing requirements.

\section{Payers/Financers (Public and Private)}

- Decisions may be made to favor regions (building new hospital or new health center, or providing expensive medical equipment as MRI, CT scan, etc..) governed by political allies, rather than following criteria of equity and efficiency.

\section{Health care providers (hospitals, doctors, nurses, pharmacists)}

- The extent that private providers provide un-needed services (admission, operation, procedure, test) more costly services or drugs for financial gains.

- The extent that private providers may refer patients to specific pharmacy, lab, X-ray center, doctor, etc. for financial gains.

- The extent of perceiving MOH staff as having a tendency to be less productive, provide less care, come late to work, and leave work early.

- The extent of steeling drugs or supplies from public hospitals and health centers.

- The extent of taking bribes from patients for services which are supposed to be free.

\section{Patients}

- $\quad$ Patients may try to get free or subsidized care by under reporting their personal or family income.

- $\quad$ The extent that patients may misrepresent their enrollment in an insurance plan by using the insurance cards of friends or family members.

- The extent that patients may bribe or deceive a doctor to obtain benefits for non-health issues, such as a health certificate to obtain a driver's license, to avoid military service or to obtain disability payments.

\section{Suppliers}

- The extent that pharmaceutical companies pay incentives to doctors encourage the use of their product such as distributing free samples, gifts, sponsored trips or training courses.

- Suppliers may bribe procurement officers to authorize low quality equipment or repackaged expired medications.

- Suppliers can persuade providers to use their products at inflated prices, even when cheaper, equally effective alternatives are available.

\section{Copyrights}

Copyright for this article is retained by the author(s), with first publication rights granted to the journal.

This is an open-access article distributed under the terms and conditions of the Creative Commons Attribution license (http://creativecommons.org/licenses/by/4.0/). 